\title{
ANATOMY OF JUNGLE CAT SKULL (FELIS CHAUS, SCHREBER, 1777)
}

\author{
P.O. Nameer ${ }^{1}$, P.O. Naseer ${ }^{2}$, M.O. Ipe ${ }^{3}$ and P.A. Ommer ${ }^{4}$ \\ ${ }^{1}$ Assistant Professor, Department of Wildlife Sciences, College of Forestry, Kerala Agricultural University, KAU (PO), Thrissur, Kerala 680656, \\ India. \\ ${ }^{2}$ Research Biologist, Research Animal Facility, Faculty of Medicine and Health Sciences, UAE University, United Arab Emirates \\ ${ }^{3}$ Manathra, Eraviperur, Kerala, India. \\ ${ }^{4}$ Professor and Head (Retd.), Department of Anatomy, College of Veterinary and Animal Sciences, Kerala Agricultural University, Mannuthy, \\ Thrissur, Kerala, 680651, India. \\ Emails: ${ }^{1}$ nameer@vsnl.com; ${ }^{2}$ arcadian@emirates.net.ae; ${ }^{4}$ ahmedommer@satyam.net.in
}

\begin{abstract}
A detailed description on the anatomy of the skull of Jungle Cat (Felis chaus) is presented in the paper. In addition, morphological features of mandible as well as dentition of the Jungle Cat are also dealt with. In general, anatomical features of these organs of Jungle Cat are more or less similar to that of domestic Cat with minor differences.
\end{abstract}

\section{Keywords}

Anatomy, skull, Felis chaus, Jungle Cat

\section{Introduction}

Carnivores being predators show certain anatomical peculiarities. They have a large brain case, the orbit usually confluent with the temporal fossa, large turbinal bones, and their complex form provide a large surface area for olfactory epithelium. The eyes are set forward permitting focused spatial vision (binocular vision) and have a field of vision of only $20^{\circ}$. On the other hand, rabbits and hares, which are prey animals, have a field of view of $150^{\circ}$ to $170^{\circ}$.

The anatomy of domestic cat (Felis domesticus) has been well documented (Crouch, 1969; Getty, 1977; Nickel et al., 1979, 1986). Pocock (1939) described five subspecies of Felis chaus from the then British India and gave cranial measurements. The one subspecies that occurs in southern India and Sri Lanka is Felis chaus kelaarti. An attempt has been made in this paper to record a detailed description of the anatomy of the skull, mandible and dentition of the Jungle Cat.

\section{Material and Methods}

Skulls of three specimens, two females and one male, obtained from the Ranni Forest Division of Kerala formed the material for the present study. The skulls were macerated and cleaned using standard anatomical techniques and various measurements of the skull were taken using a digimatic caliper (Mitutoyo ${ }^{\mathrm{TM}}$ ).

The cranial measurements that were taken include

a. Total length (TL), which was measured from the nuchal crest to the rostral end of the interincisive suture,

b. Condylobasal length (CL) which is the distance from the posterior (caudal) edge of the occipital condyles to the anterior tip of the premaxillaries (incisive bone),

c. Zygomatic width (ZW) the distance between the summits of the zygomatic arches,

d. Interorbital width (IW) the distance between the centre of the medial border of the orbit,

e. Maxillary width (MW) measured between the posterior border of the molars of the upperjaw, and

f. Mandibular length (ML): distance between the rostral end of the mandibular symphysis to the caudal aspect of the condyloid process.

g. $\mathrm{PM}^{4}$ the width of the $4^{\text {th }}$ premolar of the upper jaw

h. $M_{1}$ the width of the first molar of the lower jaw

The measurements made were then compared with similar measurements given by Pocock (1939).

\section{Results and Discussion}

The various cranial measurements of the Jungle Cat (Felis chaus) are given in Table 1. The total length of the skull ranged from 111.7 to $102.0 \mathrm{~mm}$, while that of the condylobasal length ranged from 95.3 to $85.1 \mathrm{~mm}$. The zygomatic width ranged from 76.4 to $66.5 \mathrm{~mm}$. Table 2 shows the skull measurements of (Felis chaus kelaarti) as explained by Pocock (1939) for comparison. For the domestic cat the length and width of the skull are $90 \mathrm{~mm}$ and 
Table 1. Skull measurements (in mm) of Jungle Cat (Felis chaus)

\begin{tabular}{lllllllll}
\hline Sex & TL & CL & ZW & IW & MW & ML & PM $^{4}$ & M $_{1}$ \\
\hline Male & 111.7 & 95.3 & 76.4 & 20.3 & 27.4 & 78.6 & 11.9 & 9.7 \\
Female & 102.0 & 85.1 & 66.5 & 18.3 & 24.9 & 67.5 & 10.7 & 8.3 \\
Female & 105.3 & 87.7 & 69.7 & 18.4 & 24.8 & 71.1 & 11.2 & 8.4 \\
\hline
\end{tabular}

TL - total length; CL - condylobasal length; ZW - zygomatic width; IW - interorbital width; MW - maxillary width; ML - mandibular length

60mm respectively (Roberts, http://www.91.k12.id.us/www/ skyline/teackers/robertsd/Cat.)

\section{Description of the skull}

The skull is divided into neurocranium, which protects the brain and the splanchnocranium forming the facial skeleton. The division between the cranium and the face is determined by the ethmoid bone, which lies deep within the skull. At certain points the superficial bones of both the cranium and face overlap this division.

Caudal surface (Figs. $1 \& 2$ ): The caudal aspect of the skull is formed by the occipital bone, which is roughly triangular in shape. Dorsorostrally the occipital bone articulates with the paired parietal bones, laterorostrally it articulates with the sphenoid bone. The lateral borders of the occipital bone form the nuchal crest. Mid dorsally the nuchal crest is modified to form the external occipital protuberance. The opening which the occipital bone encloses is the foramen magnum. Lateral to the foramen magnum are the smooth articular occipital condyles.

Table 2. Skull measurements (in $\mathrm{mm}$ ) of Jungle Cat (Felis chaus kelaarti) given by Pocock (1939).

\begin{tabular}{lllllllll}
\hline Sex & TL & CL & ZW & IW & MW & ML & PM $^{4}$ & M $_{1}$ \\
\hline Adultmale & 116 & 105 & 75 & 20 & 28 & 76 & 13 & 11 \\
Sub audltmale & 110 & 100 & 71 & 19 & 26 & 72 & 12 & 9 \\
Adult female & 103 & 90 & 67 & 18 & 24 & 67 & 12 & 9 \\
Adult female & 105 & 98 & 66 & 17 & 23 & 70 & 11.5 & 9 \\
Adultfemale & 101 & 93 & 70 & 18 & 24 & 67 & 12 & 9 \\
Adult female & 98 & 90 & 66 & 18 & 23 & 64 & 11 & 9 \\
\hline
\end{tabular}

TL - total length; CL - condylobasal length; ZW - zygomatic width; IW - interorbital width; MW - maxillary width; ML - mandibular length

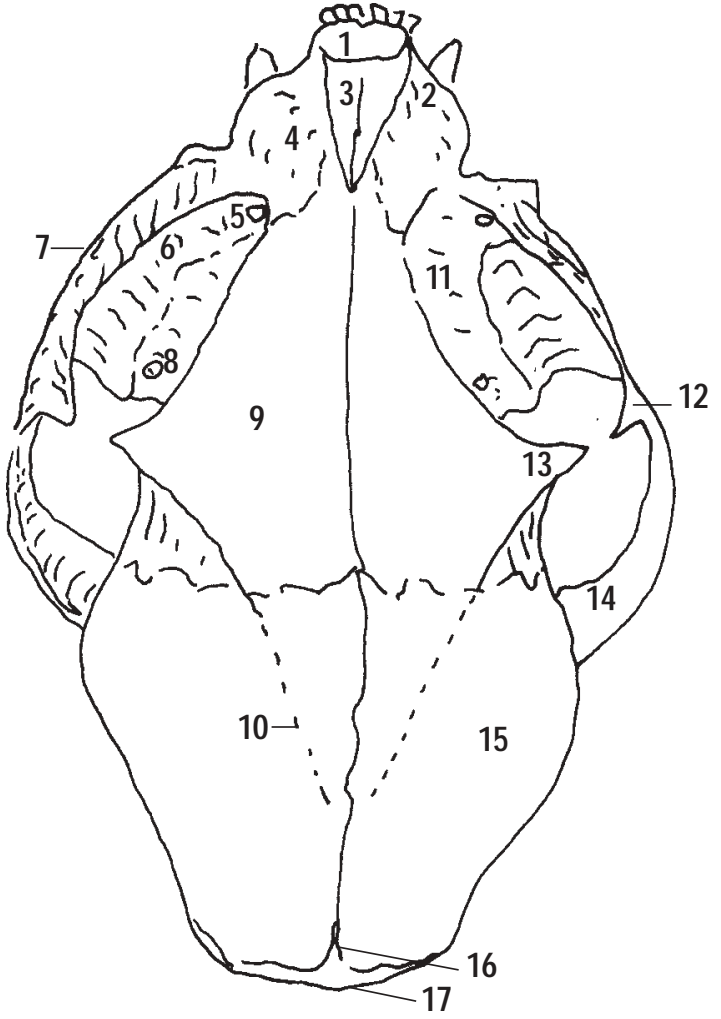

Figure 1. Dorsal view of the skull of Jungle Cat

1 - piriform aperture; 2 - incisive bone; 3 - nasal bone;

4 - maxilla; 5 - lacrimal foramen; 6 - lacrimal bone;

7 - zygomatic bone; 8 - major palatine foramen;

9 - frontal bone; 10 - temporal bone; 11 - palatine bone; 12 - frontal process of zygomatic bone; 13 - zygomatic process of frontal bone;

14 - zygomatic process of temporal bone; 15 - parietal bone; 16- interparietal bone; 17 - occipital bone

Dorsal surface (Figs. 1, $2 \& 3$ ): The dorsal surface of the neurocranium consists of the paired parietal and the paired frontal bones. The roughly quadrilateral shaped parietal bones cover most of the dorsum of the cranial cavity. Rostrally they articulate with the frontal bone, ventrally with the temporal bone, caudally with the occipital bone and medially with the opposite parietal bone. Caudally the external sagittal crest is formed at the interparietal suture. The interparietal bone is usually fused with the occipital bone prenatally. The temporal line runs rostrally from the sagittal crest to the zygomatic process of the frontal bone. It is the dorsal limit of the temporal fossa.

The frontal bones have an irregular shape and contribute to the formation of the cranial cavity rostrodorsally and to the formation of the face and orbit. They articulate with the parietal bone 


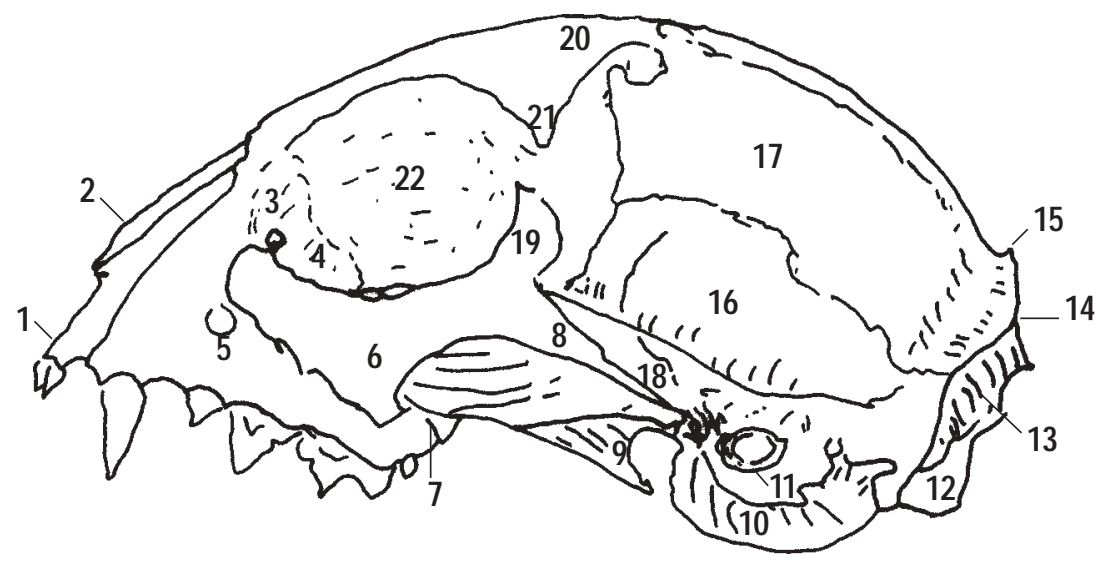

Figure 2. Lateral view of the skull of Jungle Cat

1 - incisive bone; 2 - nasal bone; 3 - lacrimal foramen; 4 - lacrimal bone; 5 - infraorbital foramen; 6 - zygomatic bone;

7 - maxillary tuber; 8 - temporal process of zygomatic bone; 9 - pterygoid bone; 10 - tympanic bulla;

11 - external acoustic meatus; 12 - occipital condyle; 13 - occipital bone; 14 - nuchal crest;

15 - external occipital protuberance; 16- squamous temporal; 17 - parietal bone; 18 - zygomatic process of the temporal;

19 - frontal process of zygomatic bone; 20 - frontal bone; 21 - zygomatic process of frontal bone; 22 - orbit

caudally, the nasal, maxilla and lacrimal bones rostrally; and the sphenoid and palatatine bones ventrally. The two frontal bones meet medially, its rostral end diverge forming a notch into which the caudal part of the two nasal bones fit together. Dorsally, the frontal bone is flattened. The zygomatic (supra orbital process) projects lateroventrally. A midline depression, frontal fossa, seen in the domestic cat at the rostral part of the frontal bone, is not seen in the case of the Jungle Cat.

Rostral surface (Figs. $1 \& 3$ ): Rostral to the frontal bone are the nasal and maxillary bones. The nasal bone articulates with the frontal bone caudally, with the maxillary bone laterally and with the opposite nasal bone medially.

The maxillary bone is an irregular shaped bone, which articulates dorso-caudally with the frontal bone, medially with the nasal bone, rostrally with the incisive bone and caudo-laterally with the lacrimal, zygomatic and palatine bones.

The incisive bone is a small bone in which the incisor teeth are rooted. It articulates caudolaterally with the maxillary bone, caudomedially with the nasal bone and medially with the opposite incisive bone. The incisive and nasal bones enclose the piriform aperture (Figs. 1 \& 2).

Lateral surface (Figs. 2, $3 \& 4$ ): The temporal bone is the most prominent bone which forms the lateral aspect of the neurocranium. It consists of squamous, tympanic and petrous parts. The squamous part forms the lateral wall of the neurocranium and articulates with the occipital bone caudally, the parietal bone dorsally, the sphenoid bone rostrally and the tympanic and petrous parts ventrally. The zygomatic process projects laterally and rostrally from the squamous part. The temporal crest is a ridge of bone, which extends caudally from the zygomatic process to the occipital bone. The mandibular fossa is a smooth, elongated depression in the ventral aspect of the zygomatic process. It articulates with the mandible. The temporal fossa is the area of the squamous temporal and parietal bones from which the temporal muscle arises. The tympanic part of the temporal bone is ventral to the squamous part and its most prominent feature is the bulbous tympanic bulla. The large lateral opening into the tympanic cavity is the external acoustic meatus through which one can sometimes see the malleus attached to the tympanic membrane. The petrous part of the temporal bone is not visible externally except for the mastoid process.

The zygomatic bone (Figs. $2 \& 3$ ) articulates with the zygomatic process of the temporal bone caudally and with the zygomatic process of the maxillary bone rostrally. These three structures form the zygomatic arch. The facial crest is the lateral ridge on the zygomatic bone. The temporal process projects caudally to articulate with the temporal bone. The frontal process projects dorsally toward the zygomatic process of the frontal bone. These two structures are joined only by an orbital ligament.

The orbit is the cavity containing the eye and lies at the junction between the cranium and the face and is formed by bones of 


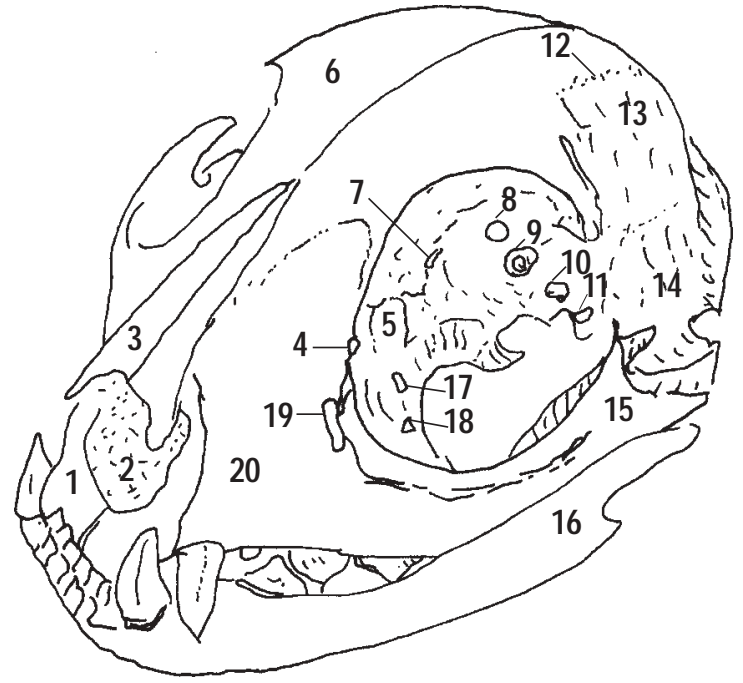

Figure 3. Rostrolateral view of the bony orbit of the skull of Jungle Cat

1 - incisive bone; 2 - piriform aperture; 3 - nasal bone;

4 - lacrimal foramen; 5 - lacrimal bone; 6 - frontal bone;

7 - ethmoid foramen; 8 - optic canal; 9 - orbital fissure;

10 - round foramen; 11 - oval foramen; 12 - temporal line; 13 - parietal bone; 14 - squamous temporal; 15 - zygomatic bone; 16 - mandible;

17 - sphenopalatine foramen; 18 - major palatine foramen; 19 - finfraorbital foramen; 20 - maxilla

both regions. Its rostral limits are formed by the frontal, lacrimal, maxillary, and zygomatic bones. The orbital opening has a complete bony rim in ruminants and equines, whereas there is a dorso-lateral gap in pigs and carnivores, which is closed by the orbital ligament (Ommer \& Harshan, 1995). In the macerated skull of the Jungle Cat there is a wide gap at the caudal aspect of the orbital rim and in one of the specimens a fibrous ligament closes this gap. The medial wall of the orbit is formed by frontal, lacrimal, wing of presphenoid and perpendicular plate of the palatine bone. The orbit communicates with the cranial cavity through many foraminae (Fig. 3). From dorsal to ventral are: (i) ethmoidal foramen (ii) optic foramen (iii) orbital fissure (iv) round foramen (v) oval foramen. The ventral wall of the orbit is rostrally located and is formed by the maxillary bone. The pterygo-palatine fossa is found above the last cheek teeth, deep down in the orbit. The pterygo-palatine fossa contains three foraminae:

(a) the maxillary foramen which leads into the infraorbital canal, (b) the sphenopalatine foramen which opens into the nasal cavity, and (c) the caudal palatine foramen which connects with the palatine canal.

Ventrally in the orbital region the medial bony wall is formed by

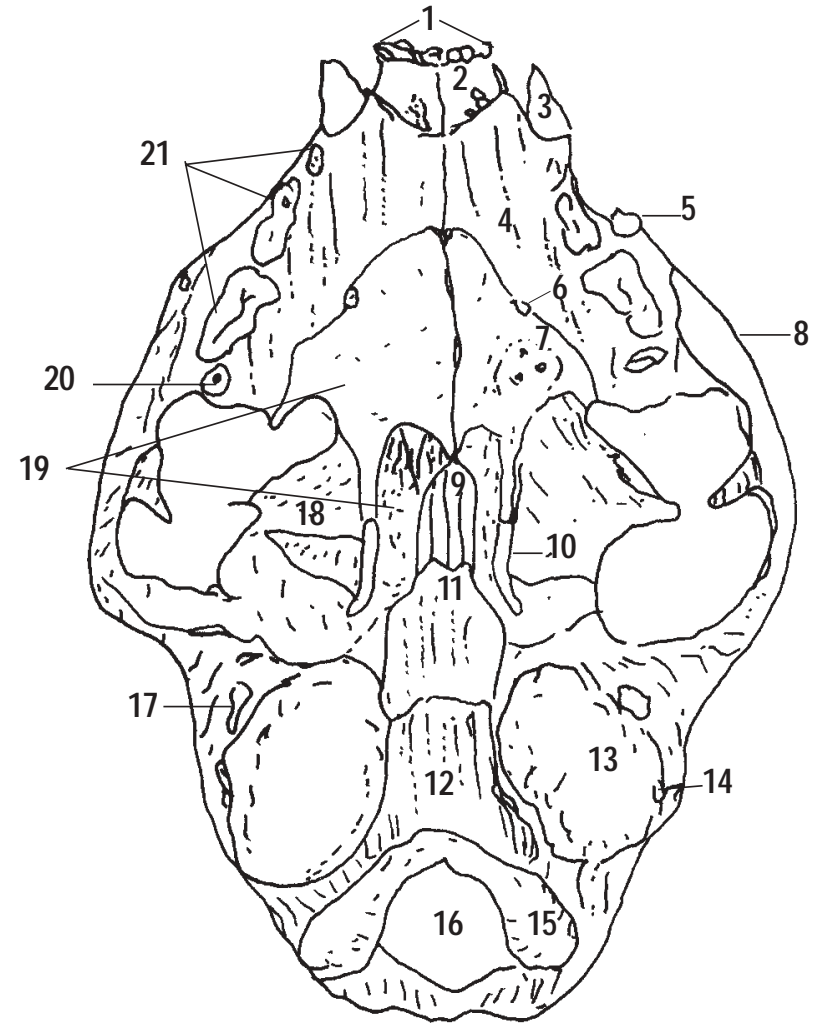

Figure 4. Ventral view of the skull of Jungle Cat 1 - incisors; 2 - incisive bone; 3 - canine; 4 - maxilla; 5 - infraorbital foramen; 6 - major palatine foramen; 7 - minor palatine foramen; 8 - zygomatic bone;

9 - presphenoid; 10 - pteryfoid bone; 11 - basisphenoid; 12 - occipital bone; 13 - tympanic bulla;

14 - stylomastoid foramen; 15 - occipital condyle; 16 - foramen magnum; 17 - external acoustic meatus; 18 - frontal bone; 19 - palatine bone; 20 - molar; 21 - premolar

the sphenoid bone caudally and by the palatine bone rostrally. The irregular shaped sphenoid bone consists of two parts, the presphenoid and the basisphenoid. The basisphenoid is the more caudal of the two. It articulates caudally with the temporal and occipital bones, ventrally with the pterygoid bone, and rostromedially with the frontal and presphenoid bones. The wing of the basisphenoid bone projects dorsally between the temporal and frontal bones.

The presphenoid bone articulates dorsally with the frontal bone, ventrally and rostrally with the palatine and ethmoid bones, caudally with the basisphenoid bone. The wing of the presphenoid bone projects between the frontal and palatine bones and contains the optic canal. 


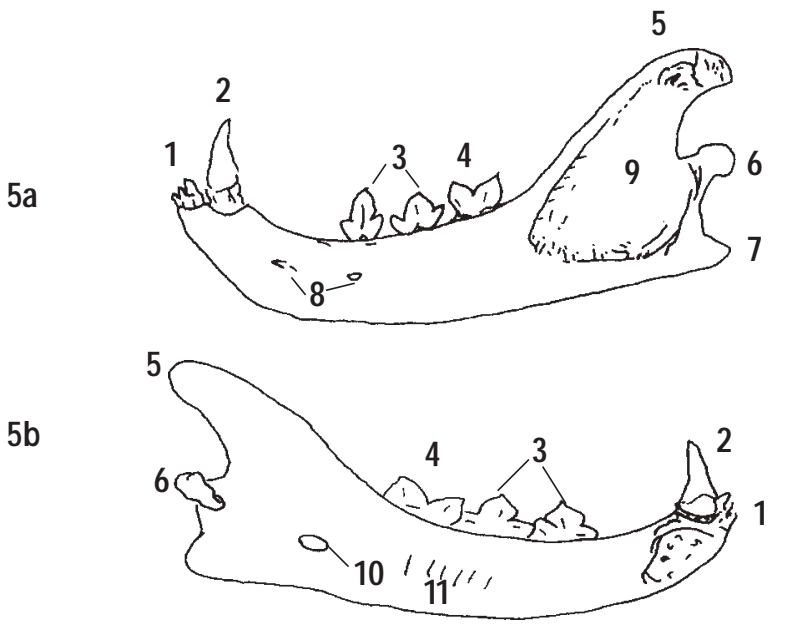

Figure 5a. Ventral view of the skull of Jungle Cat Figure $5 \mathrm{~b}$. Medial view of the skull of Jungle Cat 1 - incisors; 2 - canine; 3 - premolar; 4 - molar; 5 - coronoid process; 6 - condyloid process; 7 - angular process; 8 - mental foramen; 9 - masseteric fossa; 10 - mandibular foramen; 11 - mylohyoid line

Ventral surface: The hard palate (Fig. 4) is formed by the incisive, maxillary and palatine bones. The alveolar arch in the incisive bone contains three alveoli for the incisor teeth. Caudal to this is the palatine fissure at the level of the canine teeth. The alveolar arch in the maxillary bone contains alveoli for the canine, premolar, and molar teeth. Palate presents major palatine foramen and minor palatine foramen. The pterygoid bone is located ventral and lateral to the sphenoid bone and caudal to the palatine bone. The caudoventral projection from the pterygoid bone is the hamulus. The tympanic bulla is also a prominent feature of the ventral aspect of the skull. The stylomastoid foramen opens ventrally between the tympanic bulla and the mastoid process. The jugular foramen is located caudomedially between the tympanic bulla and the occipital bone. The hypoglossal canal opens into the caudomedial aspect of the jugular foramen.

The mandible: The mandibular bones (Figs. 5a \& 5b) are paired, contain the ventral dental arcade and articulate with the skull at the mandibular fossa. The incisive part of the body of the mandible consists of an alveolar arch, which bears the incisor teeth. The molar part of the mandible bears alveoli for the ventral cheek teeth. Interalveolar septa are found between the teeth. The medial aspect of the mandible is roughened rostrally at the mandibular synchondrosis where the two mandibles articulate. The mental foraminae are located on the rostrolateral aspect of the mandible. These foraminae are seen at the levels of the

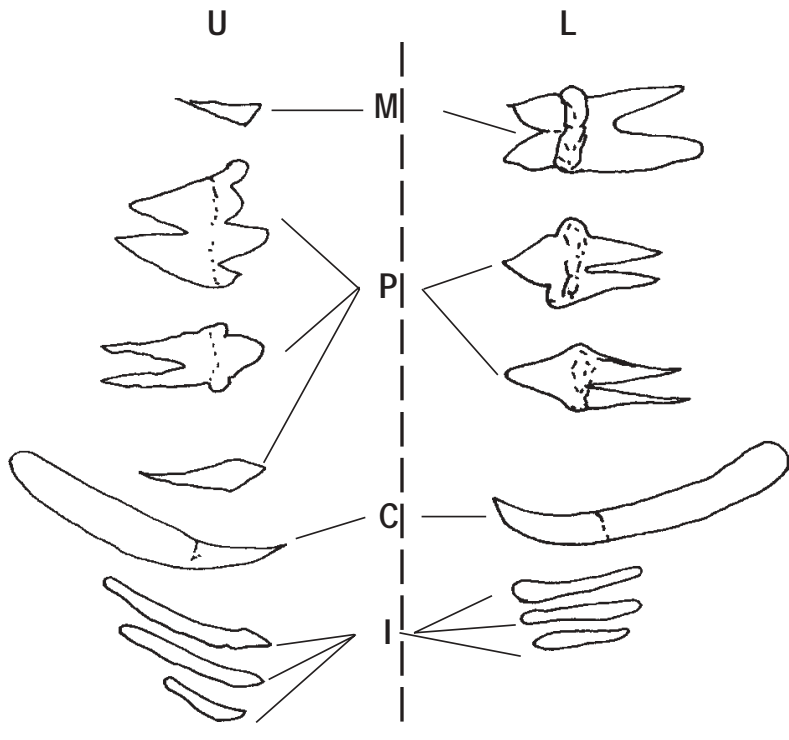

Figure 6. Teeth of Jungle Cat

$U$ - upper teeth; $M$ - molars; C - canine; $L$ - lower teeth; $P$ - premolars; I - incisors second incisor, between canine and first cheek tooth and ventral to caudal edge of the first cheek tooth.

The ramus of the mandible runs vertically. The medial surface of ramus is smooth. The mandibular foramen is located near the junction of the ramus with the body. The lateral surface of the mandibular ramus presents masseteric fossa for lodging of the masseter muscle. The condylar process is the smooth, elongated, round structure which articulates with the mandibular fossa. The angular process projects caudally from the ventral border of the mandible. The coronoid process projects caudodorsally and is located rostral to the zygomatic process of the temporal bone and medial to the zygomatic arch in the intact animal. The mandibular notch is the concave surface between the coronoid and condylar processes.

Dentition: The formula of the permanent teeth of the Jungle Cat is as follows, 2 (I3/3 - C 1/1 - P 3/2 - M 1/1) = 30 (Fig. 6).

Incisor teeth: The incisors, the lower ones, are relatively small. They increase in size from 1 to 3 . The upper teeth are more curved than the lower.

Canine Teeth: The canine tooth has a pointed, but curved, crown. The root is somewhat longer than the crown and is round, thick and blunt at the apex. The crown of the upper canine has a 
slightly concave inner surface. Vertical ridges and grooves mark the rounded outer surface. The crown of the lower canine is a bit shorter and more curved. The rostral part of the outer surface is convex and rigid. The caudal part of the lateral surface is slightly twisted and concave longitudinally.

Cheek teeth: The first upper premolar $\left(\mathrm{P}^{2}\right)$ is small; single rooted and has a laterally compressed conical crown. The second upper premolar $\left(\mathrm{P}^{3}\right)$, the first lower premolar $\left(\mathrm{P}^{3}\right)$ and the second lower premolar $\left(\mathrm{P}^{4}\right)$ resemble each other. The crown is compressed medio-laterally and is more convex laterally than medially. There is a central principal cusp with a smaller basal cusp on the rostral and caudal aspect of the principal cusp. The width of large last upper premolar $\left(\mathrm{P}^{4}\right)$ ranges from 11.2 to $11.9 \mathrm{~mm}$., which is larger than $\mathrm{p}^{3}$, presents a central principal cusp, two rostral basal cusps, and a single caudal basal cusp. The principal and caudal basal cusps are high, sharp and compressed medio-laterally. This is a carnassial or sectorial tooth. The upper molar is greatly reduced in size and is transversely oriented. The crown has a small tubercular grinding surface. The large lower molar is a carnassial tooth and its width ranges from 8.4 to $9.7 \mathrm{~mm}$. It has two large cusps which are compressed mediolaterally. The lateral side of the crown is convex, whereas there is a pit between the cusps on the medial side. The upper group of incisors occupies more space than the lower one, so that the upper corner incisor tooth lies between the lower corner incisor and the lower canine. The lower canine passes rostral and medial to the upper canine.
The upper dental arch is wider than lower (anisognathism) and as a result of this, the lingual surface of the upper teeth slides over the vestibular surface of the lower teeth when jaws are being closed (shearing action). Accordingly, the structure of the temperomandibular joint permits only dorsoventral movement of the mandible, although slight lateral movement of the mandible is possible for the shearing action of the teeth to come into play on one side or other.

\section{References}

Crouch, J.E. (1969). Text Atlas of Cat Anatomy, pp.5-14. Lea and Febiger, Philadelphia .

Getty, R. (1977). Sisson and Grossman's The Anatomy of the Domestic Animals, 2: 1544-1546. The Macmillan Company of India Ltd., New Delhi.

Nickel, R., A. Schummer and E. Seiferli (1979) (Editor.). The Viscera of the Domestic Mammals. ${ }^{\text {nd }}$ edition. Verlag Paul Parey, Berlin.

Nickel, R., A. Schummer and E. Seiferli (1986). The Anatomy of the Domestic Animals Vol. 1. Verlag Paul Parey, Berlin.

Ommer, P.A. and K.R. Harshan (1995). Applied Anatomy of The Domestic Animals, p.4. Jaypee Brothers Medical Publishers (P) Ltd., New Delhi,

Pocock, P.I. (1939). The Fauna of British India including Ceylon and Burma (Vol. 1, Primates and Carnivora, in part). Taylor and Francis, London.

Roberts, D.L. Cat Skull - De Loy Roberts Collection. http:// www.D.91.k12.id.us/www/skyline/teachers/Roberts/Cat.html 